\title{
MOSCAS FRUGÍVORAS (DIPTERA: LONCHAEIDAE) EM CAFEZAIS IRRIGADOS NO NORTE DE MINAS GERAIS
}

\author{
M.G. Camargos ${ }^{1}$, C.D. Alvarenga ${ }^{1}$, T.A. Giustolin ${ }^{1}$, P.C. Strikis ${ }^{2}$ \\ ${ }^{1}$ Universidade Estadual de Montes Claros, Departamento de Ciências Agrárias, Rua Reinaldo Viana, 2630, \\ CEP 39440-000, Janaúba, MG, Brasil. E-mail: mariagisely@hotmail.com
}

\section{RESUMO}

Este trabalho teve como objetivo conhecer as espécies de moscas frugívoras (Diptera: Lonchaeidae) associadas à cultura de café, cultivada na região do projeto Jaíba, em Jaíba, norte de Minas Gerais. As coletas de moscas foram realizadas em dois cafezais de 0,5 ha cada (áreas 1 e 2) e em um cafezal de 2 ha (área 3), todos irrigados e cultivados a pleno sol com a variedade Catuaí vermelho. O levantamento desses insetos foi realizado no período de janeiro 2009 a abril de 2010, quando o cafezal estava com frutos em fase de amadurecimento. Os insetos foram amostrados a partir da coleta de frutos amadurecidos e caídos no solo e também daqueles retirados diretamente da planta. Foi obtido um total de 497 indivíduos, dos quais 245 eram fêmeas e 252 machos. As espécies identificadas foram Neosilba pendula (Bezzi), N. zadolicha (McAlpine \& Steyskal) e N. inesperata (Strikis \& Prado), sendo a predominante N. pendula $(94,1 \%)$. Este é o primeiro registro de N. inesperata em Minas Gerais.

PALAVRAS-CHAVE: Neosilba, lonqueídeo, Coffea arabica, café.

\section{ABSTRACT}

FRUGIVOROUSFLIES(DIPTERA:LONCHAEIDAE) IN IRRIGATED COFFEEPLANTATIONS IN THE NORTH OF MINAS GERAIS STATE, BRAZIL. This work surveyed the frugivorous flies species (Diptera: Lonchaeidae) associated with the coffee crop of the Jaíba Project, in the north of Minas Gerais State, Brazil. Flies were collected in two coffee plantations of 0.5 ha each (areas 1 and 2) and in another one of 2 ha (area 3), all of them irrigated and grown under full sun with the red Catuaí variety. The survey of insects was carried out from January 2009 to April 2010, in the ripening phase. The insects were sampled from ripe fruits, fallen on the ground, and those picked from the plant. A total of 497 individuals were obtained, from which 245 were females and 252 were males. The identified species were Neosilba pendula (Bezzi), N. zadolicha (McAlpine \& Steyskal) and N. inesperata (Strikis \& Prado), with a predominance of N. pendula (94.1\%). This is the first record of $N$. inesperata in Minas Gerais.

KEY WORDS: Neosilba, lonchaeid, Coffea arabica coffee.

A cafeicultura na região Norte do Estado de Minas Gerais é recente, sendo os seus plantios realizados a menos de 20 anos. As áreas cultivadas com cafezais irrigados no entorno do Rio São Francisco cresceram, tendo perspectivas de tornar esta uma nova zona cafeeira do Estado. A região apresenta clima semiárido, o que poderia afetar o cultivo do café, entretanto, tem-se verificado que o calor favorece esta cultura, incrementando a produtividade e inibindo o aparecimento de algumas espécies de pragas (RIBEIRO, 2010).

As moscas frugívoras (Diptera: Tephritoidea) provocam danos indiretos nos cafezais, pois, apesar de suas larvas não atacarem as sementes dos frutos, podem provocar a queda destes na fase cereja e diminuir a qualidade da bebida (CIVIDANES et al., 1993). Esses insetos vêm assumindo grande importância econômica nos cafezais (BAETA-Neves et al., 2002; RAGA et al., 1996; SouzA et al., 2005; TORRES, 2004), pois o cafeeiro, como hospedeiro de moscas frugívoras (Tephritidae e Lonchaeidae), pode contribuir na dispersão dessas pragas para outras culturas, principalmente para áreas de fruticultura. Representantes da família Lonchaeidae foram registrados pela primeira vez na região Norte de Minas Gerais, com registro de Lonchaea sp., Neosilba pendula (Bezzi), N. zadolicha McAlpine \& Steyskal, Dasiops sp. e Neosilba sp. 4, coletados em áreas de mata seca, e exemplares

${ }^{2}$ Universidade Estadual de Campinas, Instituto de Biologia, Campinas, SP, Brasil. 
de N. glaberrima (Wied.), N. zadolicha, N. pendula, e Neosilba sp. 4 obtidos em pomares comerciais de goiaba (LOPES, 2007).

Este trabalho visou conhecer as espécies de moscas frugívoras (Diptera: Lonchaeidae) associadas à Coffea arabica cultivado sob irrigação em Jaíba, região Norte de Minas Gerais.

Oestudo foi desenvolvido em três áreas (denominadas 1, 2 e 3) de café irrigado, variedade Catuaí vermelho, localizadas no Projeto de Irrigação do Jaíba. As áreas foram selecionadas de acordo com as características de tamanho, tratos culturais e idade; as áreas 1 ( $15^{\circ} 10^{\prime} 40,1^{\prime \prime}$ S e $43^{\circ} 59^{\prime} 20,8^{\prime \prime} \mathrm{W}$, elevação $484 \mathrm{~m})$ e $2\left(15^{\circ} 10^{\prime} 27^{\prime \prime}\right.$ S e $43^{\circ} 59^{\prime}$ 32,1" W elevação 461 m) com 0,5 ha de café plantado cada uma, e a área

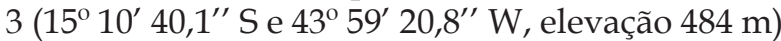
com 2,0 ha. As plantas nas três áreas estavam com cinco anos e em período de produção. Nenhuma pulverização com produtos químicos para controle de moscas frugívoras foi realizada durante o período de execução das coletas.

Foram realizadas coletas sistemáticas e aleatórias de frutos de café maduros ou em amadurecimento, no total de 32 amostras. Os frutos foram coletados da copa das árvores e também do solo, sendo considerados os recém-caídos e sem orifícios de saída de larvas. O número de frutos coletados por amostra foi variável e dependente da disponibilidade destes no campo. As coletas foram realizadas semanalmente de janeiro a junho de 2009 e de março a abril de 2010, período em que os frutos estavam maduros.

As amostras, devidamente etiquetadas (data, local, coletor), foram acondicionadas em bandejas plásticas e transportadas até o Laboratório de Entomologia da Universidade Estadual de Montes Claros (Unimontes). Os frutos foram contados, pesados e acondicionados em recipientes plásticos contendo vermiculita umedecida e fechados com tecido voile. As amostras foram mantidas em laboratório em condições controladas de temperatura $\left(27 \pm 1^{\circ} \mathrm{C}\right)$. Após 10 dias, foi realizado o peneiramento da vermiculita, bem como o exame cuidadoso da polpa de cada um dos frutos. As larvas e os pupários de lonqueídeos obtidos foram contados e transferidos para frascos de vidro contendo vermiculita umedecida, tampados com voile, visando à emergência dos adultos. Os insetos emergidos foram enviados ao Departamento de Parasitologia da Universidade Estadual de Campinas - UNICAMP, para identificação específica.

Foi obtido um total de 497 espécimes ( 245 machos e 253 fêmeas) da família Lonchaeidae, provenientes dos frutos de café coletados nas três áreas (Tabela 1). Três espécies de lonqueídeos foram identificadas: N. pendula, N. zadolicha e N. inesperata (STRIKIS; PRADO 2006; 2009). Como a identificação específica é realizada a partir da análise das estruturas da genitália dos machos (McAlpine; SteYSKal, 1982), todas as fêmeas identificadas eram do gênero Neosilba. As espécies $N$. pendula e $N$. inesperata foram as mais comuns nas áreas 1 e 3, sendo que, N. zadolicha foi constatada somente na área 1.

As espécies $N$. pendula e $N$. zadolicha já foram relatadas em cafeeiros no Brasil (AguiAR-MENEZES et al., 2007; FERNANDES, 2009; SOUZA et al., 2005; STRIKIS; PRADO, 2006). Na região Norte de Minas Gerais já havia sido constatada a infestação de frutos de goiaba por lonqueídeos (LOPES, 2007), porém trata-se do primeiro relato da associação de Lonchaeidae em frutos de café na região.

$N$. pendula foi a espécie predominantenos cafezais avaliados, representando $94,1 \%$ dos lonqueídeos emergidos (Tabela 1). Esta espécie tem sido relatada como a mais frequente em outros estudos em cafeeiros no Brasil (Del Vecchio, 1991; Fernandes, 2009). Provavelmente, $N$. pendula tenha preferência por frutos de café, pois esta espécie foi observada em pomares de goiaba, pêssego e nêspera, próximas às áreas cultivadas com café, favorecendo a sucessão hospedeira desta espécie (Souza FilHo, 2006).

Pela primeira vez em Minas Gerais há o registro de $N$. inesperata, porém há relato desta espécie associada a frutos de café no Estado de São Paulo (STRIKIS; PRADO, 2009). Embora essa espécie tenha sido coletada em menor número que $N$. pendula, ela foi mais frequente que $N$. zadolicha, que é considerada uma espécie polífaga e de grande capacidade de exploração de nichos (SouzA FiLHo, 2006).

Portanto, com este estudo, N. pendula, N. zadolicha e $N$. inesperata estão associadas a frutos de café em Minas Gerais. Os espécimes foram depositados na coleção do Laboratório de Entomologia da Unimontes, em Janaúba (MG).

Tabela 1 - Espécies de moscas frugívoras coletadas em cafezais no Município de Jaíba, MG. Período de janeiro/2009 a abril/2010.

\begin{tabular}{cccccc}
\hline Área & N.pendula & N. inesperata & N. zadolicha & Neosilba spp. (fêmeas) & Total \\
\hline 1 & 82 & 4 & 1 & 97 & 184 \\
2 & 51 & 0 & 0 & 49 & 100 \\
3 & 97 & 10 & 0 & 106 & 213 \\
\hline Total & 230 & 14 & 1 & 252 & 497 \\
\hline
\end{tabular}




\section{AGRADECIMENTO}

À FAPEMIG pelo financiamento da pesquisa e concessão de bolsas.

\section{REFERÊNCIAS}

AGUIAR-MENEZES, E.L.; SOUZA, S.A.S.; SANTOS, C.M.A.; RESENDE, A.L.S.; STRIKIS, P.C.; COSTA, J.R.; RICCI, M.S.F. Susceptibilidade de seis cultivares de café arábica às moscas-das-frutas (Diptera: Tephritoidea) em sistema orgânico com e sem arborização em Valença, RJ. Neotropical Entomology, v.36, n.2, p.268-273, 2007.

BAETA-NEVES, A.M; TOFANI, S.R.M.; GERALDO, B.S.; SILVA, E.R.. Mosca no café. Cultivar, v.4, p.34-35, 2002.

CIVIDANES, F.J.; NAKANO, O.; MELO, O. Avaliação da qualidade de frutos de café atacados por Ceratitis capitata (Wiedemann, 1824) (Diptera: Tephritidae). Scientia Agrícola, v.50, p.220-225, 1993.

DEL VECCHIO, M.C. Família Lonchaeidae (Diptera: Acalyptratae): ocorrência de espécies e respectivos hospedeiros em algumas localidades do estado de São Paulo. 1991. 58f. Dissertação (Mestrado em Biologia) Universidade Estadual de Campinas, Campinas, 1991.

FERNANDES, D.R.R. Moscas frugívoras, lepidópteros desfolhadores e seus parasitóides (Hymenoptera) associados a cultivo de café, em Cravinhos, SP. 2009. 74p. Dissertação (Mestrado em Entomologia Agrícola) - Universidade Estadual Paulista, Faculdade de Ciências Agrárias e Veterinárias, Jaboticabal, 2009.

LOPES, E.N. Espécies de Lonchaeidae (Diptera, Tephitoidea) em ares de mata nativa e em pomares de goiaba no norte de Minas Gerais. 2007. 39 f. Trabalho de Conclusão de Curso (Graduação em Agronomia) - Universidade Estadual de Montes Claros, Janaúba, 2007.

McALPINE, J.F.; STEYSKAL, G.C. A revision of Neosilba McAlpine with a key to the world genera of Lonchaeidae (Diptera). Canadian Entomology, v.114, p.105-137, 1982.

RAGA, A.; SOUZA FILHO, M.F. de; ARTHUR, V.; MARTINS, A.L.M. Avaliação da infestação de moscas-das-frutas em variedades de café (Coffea spp.). Arquivos do Instituto Biológico, São Paulo, v.63, n.2, p.59-63, 1996.

RIBEIRO, L. Invasão dos cafezais no Norte de Minas Gerais. Cafeicultura: a revista do agronegócio café. 2010. Disponível em: <http:/ / www.revistacafeicultura.com.br/ index.php?tipo=ler\&mat=32225>. Acesso em: 28 jun. 2010.

SOUZA FILHO, M. F. de. Infestação de moscas-das-frutas (Diptera: Tephritidae e Lonchaeidae) relacionada à fenologia da goiabeira (Psidium guajava L.), nespeira (Eryobotrya japonica Lindl.) e do pessegueiro (Prunus pérsica Batsch). 2006. 125p. Tese (Doutorado em Entomologia) - Universidade de São Paulo, Escola Superior de Agricultura "Luiz de Queiroz", Piracicaba, 2006.

SOUZA, S.A.S.; RESENDE, A.L.S.; STRIKIS, P.C.; COSTA, J.R.; RICCI, M.S.F.; AGUIAR-MENEZES, E.L. Infestação natural de moscas frugívoras (Diptera: Tephritoidea) em café arábica, sob cultivo orgânico arborizado e a pleno sol, em Valença, RJ. Neotropical Entomology, v.34, n.4, p.639-648, 2005.

STRIKIS, P.C.; PRADO, A.P. Neosilba (Tephritoidea: Lonchaeidae) Species Reared from Coffee in Brazil, with description of a New Species. In: INTERNATIONAL SYMPOSIUM ON FRUIT-FLIES OF ECONOMIC IMPORTANCE, 7., 2006, Salvador. Proceedings. Salvador: Moscamed, 2006. p.187-193.

STRIKIS, P.C.; PRADO, A.P. Lonchaeidae associados a frutos de nêspera, Eryobotria japonica (Thunb.) Lindley (Rosaceae), com a descrição de uma espécie nova de Neosilba (Diptera: Tephritoidea). Arquivos do Instituto Biológico, São Paulo, v.76, n.1, p.49-54, 2009. Disponível em: < http://www.biologico.sp.gov.br/docs/arq/ v76_1/strikis.pdf.> Acesso em: 28 jun. 2010.

TORRES, C.A.S. Diversidade de espécies de moscas-das-frutas (Diptera: Tephritidae) e de seus parasitóides em cafeeiro (Coffea arabica L.). 2004. 71 p. Dissertação (Mestrado em Agronomia) - Universidade Estadual do Sudoeste da Bahia, Vitória da Conquista, 2004.

Recebido em $4 / 10 / 10$

Aceito em 30/10/11 